\title{
Anaemia and hiatus hernia: experience in 450 patients
}

\author{
COLINW. O. WINDSORAND J. LEIGH COLLIS
}

From the United Birmingham Hospitals

Since a correlation between hiatus hernia and anaemia was established in 1931 by Segal, numerous attempts have been made to elucidate its cause. Loss of blood may occur from the oesophagus or from associated peptic ulceration of the stomach or duodenum, but these sources do not account for the majority of cases presenting with anaemia. In this paper it is suggested that the most common cause of blood loss is haemorrhage from the area of the stomach which rides over the crus at the neck of the hernial sac, and evidence is presented which substantiates this view.

\section{HISTORICAL REVIEW OF ANAEMIA AND HIATUS HERNIA}

The association of gastric ulceration and large diaphragmatic hernias is not a new one; Bright (1836) described a fatal case which died of respiratory complications. Truesdale (1932) reviewed 17 cases of gastric ulcer reported since 1904 in patients with various types of diaphragmatic defects. He points out that several authors mentioned the complication of bleeding from the ulcer as well as perforation. Hiatus hernia as a distinct entity causing anaemia and often silent blood loss was recognized and reported by Segal (1931) and Bock, Dulin, and Brooke (1933). Since that time many attempts have been made to elucidate the aetiology.

Segal (1931), reviewing the situation, concluded that anaemia was caused by bleeding from the stomach due to venous congestion, arterial obstruction, and inflammation. Weight was added to this concept when Bock et al. (1933) found intense venous congestion of the stomach in postmortem material taken from patients with the associated conditions. Harrington (1940), reviewing his own experience, put forward the view that haemorrhage in hiatus hernia was due to ulceration of either the oesophagus or the stomach near to the cardia caused by the to and fro sliding motion of this area in the hernial ring. He also felt that regurgitation of acid into the oesophagus was a contributory factor. Agreeing with Harrington as to the site of the bleeding, small but repeated blood losses were said to occur by Murphy and Hay (1943), who successfully treated their patients by administering iron. Gastroscopy was used in an attempt to identify the bleeding site by Sahler and Hampton (1943), who did note gastritis and erosions of mucosa in some anaemic patients, but overall the findings were inconclusive. The literature was reviewed again in 1949 by Schwartz and Blumenthal, but no new conclusions were reached. However, in the 20 new cases that they reported, all other probable bleeding sites were excluded and the hiatus hernia was beyond doubt incriminated as the cause of the anaemia.

The significance of oesophageal ulceration, due to reflux, as a prime cause of haemorrhage was challenged by Clerf, Shallow, Putney, and Fry (1950). They demonstrated ulceration in 39 of 110 patients with hiatus hernia, but found anaemia in only nine. Following along similar lines, Phear (1957) found that reflux did not seem to cause anaemia unless it was associated with a hernia. $\mathrm{He}$ cited 87 cases of hiatus hernia and 20 cases with reflux and no hernia; 33 were anaemic in this group and all were found to be associated with a hernia. A case report by Roussak and Eden (1947) of a paraoesophageal hernia with anaemia seemed to be a prelude to observations based on the difference between the types of hiatus hernia where anaemia is concerned. Grimes and Stephens (1957) were aware that anaemia could be present in patients with paraoesophageal hernias which only infrequently had gastro-oesophageal incompetence. Later this point was amplified when Johns and Clements (1961) noted that patients with this type of hernia had a higher incidence of anaemia than did those with the sliding variety. In listing possibilities, the same authors suggested iron-deficient diets and lack of 'gastric factors' as other probable causes of this syndrome. Against the trend in turning attention from the oesophagus, De Vito, Listerud, Nyhus, Merendino, and Harkins (1959) and Hood and McChesney (1962) presented 
good post-mortem and endoscopic findings respectively establishing a definite relationship between haematemesis and oesophagitis. However, Windsor (1964), investigating post-gastrectomy reflux, found this to be present in $40 \%$ of his patients, but found no increased incidence of anaemia in this group.

The need to eliminate other sites of gastrointestinal haemorrhage before incriminating the hiatus hernia is suggested by Palmer (1963), who found a high incidence of duodenal and gastric ulcer and oesophageal varices in his collection of 500 cases having sliding hernias.

Attempts to correlate microscopic changes in the mucosa of the herniated stomach with anaemia were made by Forstner and Bogoch (1963). They raised the possibility that macroscopically unrecognized sites of bleeding may be present in the stomach when they found changes in the lamina propria associated with anaemia. Dagradi, Killeen, and Schindler (1958) also studied the herniated stomach and were able to detect by gastroscopy macroscopic changes of gastritis in $45 \%$ of hiatus hernia patients.

Defective absorption of iron in patients with hiatus hernia is suggested by Michaelides and Philis (1959) and Loeper, Rameix, and Moges (1963) as being a common cause of anaemia. The former cites a single case in which he found that ferric iron was not absorbed unless administered with ascorbic acid or intrinsic factor. Loeper $e t$ al. (1963) investigated 12 patients and found that the low serum iron levels in six did not rise as a result of the ingestion of iron during the six hours of his test. These are interesting observations, as pointed out in a leading article in the British Medical Journal (1964), but it is not felt that the findings warrant the drawing of any generalized conclusions.

These are some of the thoughts and trends in the understanding of the relationship between hiatus hernia and anaemia over the past 40 years. Table I gives some collected data on the incidence of anaemia encountered.

\section{MATERIAL}

Four hundred consecutive cases of hiatus hernia, selected only because they had symptoms severe enough to require operative treatment, form the basis for this study. Additional information was obtained from a further consecutive series of 50 cases with a short oesophagus and stricture.

Special follow-up was reserved for 59 patients who either were anaemic or had bled from the upper gastro-intestinal tract at the time of admission to hospital. Bleeding from a duodenal or low
T A B LE I

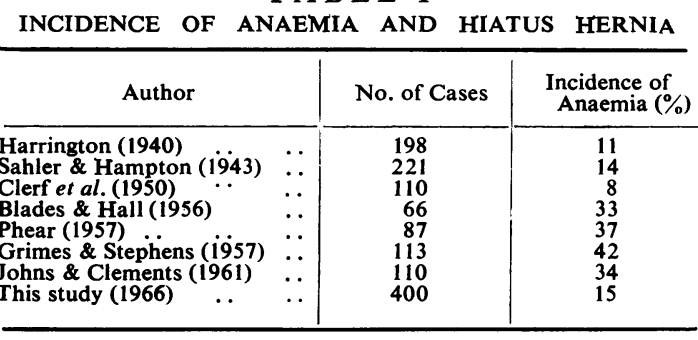

gastric ulcer excluded them from this follow-up; other possible sites of blood loss were investigated and not found to play a significant role in the cause of anaemia in this group. Of the 59 patients asked to attend hospital, eight were dead and three untraced at the time of review, which varied between one and 13 years post-operatively. On 100 non-anaemic patients with sliding hernia taken from the original 400 , certain special studies were carried out.

\section{FINDINGS}

GENERAL The arbitrary level of haemoglobin considered to indicate anaemia was below 11.5 g. $/ 100 \mathrm{ml}$. in females and $13.5 \mathrm{~g} . / 100 \mathrm{ml}$. in males. These figures may appear to be high, but the mean haemoglobin in the anaemic group was 8.5 g. $/ 100 \mathrm{ml}$. All of the haematological data showed an iron-deficiency type of anaemia and it was assumed that this was the result of blood loss. Dietary deficiencies could be a cause of anaemia, but only nine patients were found to be taking a diet poor in iron before surgery and four of these presented with haematemesis. Diet does not seem to be a significant causative factor in the anaemic patients reported in this series.

The overall incidence of anaemia and symptoms of haemorrhage in the 400 patients was $15 \%$. Some patients presenting with haematemesis or melaena were not anaemic at the time of admission to hospital but are included in this investigation.

RESULTS OF OPERATION As a result of operative treatment in the anaemic group (Collis, 1961), the hernia was controlled in all but two cases and reflux in all but four. There was no recurrence of melaena or haematemesis and the mean rise of haemoglobin was $5.4 \mathrm{~g} . / 100 \mathrm{ml}$. (range 0 to 11.4 g. $/ 100 \mathrm{ml}$.).

\section{DETAILED FINDINGS}

A comparison of the paraoesophageal and sliding hernia groups revealed certain features significant in the aetiology of the anaemia. Where relevant the additional facts obtained from the non- 
anaemic group and the short oesophagus group are discussed in relation to the conclusions drawn. Of the 400 patients, 326 had sliding hernias, 59 paraoesophageal, and 15 mixed hernias. For simplicity, the mixed hernias have been considered with the paraoesophageal ones throughout this paper.

Table II shows that anaemia is nearly three times more common in the paraoesophageal hernia patients than in those with a sliding hernia. The incidence of anaemia in the patients with a short oesophagus and hiatus hernia is midway between the two.

T A B L E I I

INCIDENCE OF ANAEMIA

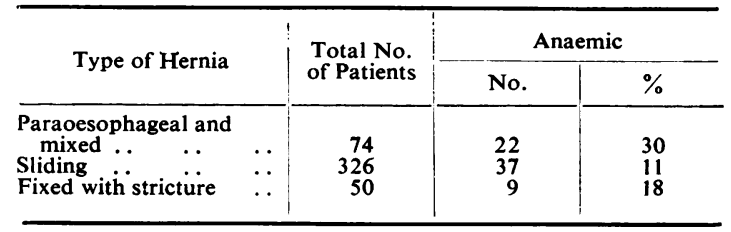

Radiological reflux was present in all of the sliding hernia group and in one of the paraoesophageal group, where it was associated with a mixed-type hernia (Table III).

\section{T A B L E II I}

INCIDENCE OF RADIOLOGICAL REFLUX IN ANAEMIC PATIENTS

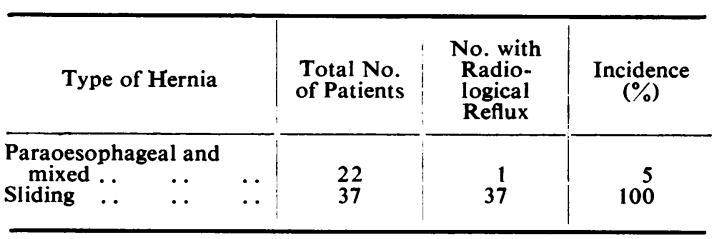

In all but six patients, pre-operative oesophagoscopy was carried out. The findings were graded as follows:

Grade I Mild oesophagitis, indicating a reddening of the mucosa ;

Grade II Moderate oesophagitis, indicating a red mucosa which bled readily as a result of mild trauma but not spontaneously ;

Grade III Severe oesophagitis, indicating frank ulceration often with spontaneous bleeding taking place.

The findings are shown in Table IV.
T A B L E I V

OESOPHAGOSCOPY FINDINGS

\begin{tabular}{l|c|c|c|c}
\hline Type of Hernia & $\begin{array}{c}\text { No. of } \\
\text { Patients }\end{array}$ & \multicolumn{2}{|c|}{ Grade of Oesophagitis (\%) } \\
\cline { 2 - 5 } & I & II & III \\
\hline $\begin{array}{c}\text { Paraoesophageal } \\
\text { and mixed }\end{array}$ & 22 & 0 & 5 & 5 \\
$\begin{array}{c}\text { Sliding (anaemic) } \\
\text { Fixed with } \\
\text { stricture }\end{array}$ & 37 & $14 \cdot 5$ & $11 \cdot 6$ & $5 \cdot 8$ \\
$\begin{array}{c}\text { Sliding (non- } \\
\text { anaemic) }\end{array}$ & 50 & 16 & 20 & 42 \\
\hline
\end{tabular}

It is clear that reflux oesophagitis is very uncommon in patients with paraoesophageal hernia, and that only about $17 \%$ of patients having anaemia and a sliding hernia have significant oesophagitis.

Further evidence that oesophagitis has little influence on the incidence of anaemia is provided by the additional information found in Tables II and IV. Patients with fixed hernias, with gross oesophagitis in $42 \%$ of cases and stricture formation in $80 \%$, have a lower incidence of anaemia than patients with no reflux at all. In the 100 cases of hernia without anaemia the pattern of oesophagitis is almost identical to that in the anaemic group.

HERNIA SIZE AND RIDING ULCERS IN ANAEMIC PATIENTS Twenty of the total 59 anaemic patients are recorded in their operation note as having had huge hiatus hernias. Five patients had high gastric ulcers occurring at the site where the stomach crossed the right crus; three of these ulcers occurred in the paraoesophageal group and two, high on the lesser curve, in the sliding group. In addition, changes varying from hyperaemia to petechial haemorrhages on the serosal surface of the stomach were found in several patients at sites corresponding to the neck of the hernial sac. These findings suggest that local trauma caused by the crura is associated with bleeding and anaemia.

ASYMPTOMATIC HERNIA WITH ANAEMIA All the patients operated on for sliding hiatus hernia had symptoms of reflux oesophagitis except for five patients whose only complaint was of weakness and malaise. These patients were in the anaemic group and had radiological confirmation of hiatus hernia with a mild degree of reflux but did not complain of heartburn. After careful investigation, the hernia was found to be the only possible cause for the anaemia. Despite the absence of oesophageal symptoms, surgical repair was carried out and in all cases the anaemia was cured. Reduc- 
tion of the stomach into the abdomen was the only change effected in these patients. This manœuvre stopped loss of blood from the upper gastro-intestinal tract and it is therefore considered likely that the site of the haemorrhage was in that portion of the stomach reduced by operation.

\section{DISCUSSION}

From the results of this investigation it is possible to exclude certain factors as likely causes of anaemia and to emphasize others as being significant.

The lower oesophagus damaged by oesophagitis is often said to be the site of blood loss in patients presenting with anaemia and hiatus hernia. From the findings in this series, oesophagitis seems to be an unlikely cause of anaemia. In patients with paraoesophageal hiatus hernia, which does not cause reflux or oesophagitis (Tables III and IV), there is a $30 \%$ incidence of anaemia. In patients with the sliding type hernia, with $100 \%$ radiological reflux, there is an $11 \%$ incidence of anaemia. These facts suggest a lack of correlation between oesophagitis and anaemia which is emphasized by two additional findings. Patients with hiatus hernia and a short oesophagus (Table IV) having gross bleeding oesophagitis $(42 \%)$ have a significantly lower incidence of anaemia (18\%) than the paraoesophageal cases. Also the oesophagoscopy findings (Table IV) show that the pattern of oesophagitis in the 100 non-anaemic cases with sliding hernia is almost identical to that in the 37 with anaemia. These highly significant findings suggest that there is little correlation between the state of the lower oesophagus and the incidence of anaemia and, furthermore, that bleeding from the lower oesophagus is unlikely to result in anaemia.

Other causes of blood loss which may be associated with hiatus hernia, such as low gastric ulcer and duodenal ulcer, have been deliberately excluded from this series. Bleeding from haemorrhoids and heavy menstrual losses have been found to be possible complicating factors in only three of the 59 patients; it is therefore reasonable to assume that the hiatus hernia has been the sole cause of anaemia in the majority of cases. It has been suggested (Johns and Clements, 1961) that patients with symptoms of hiatus hernia may take a diet deficient in iron. In nine of the cases reported here dietary restriction was significant, but four of these patients presented with haemat- emesis, which is considered to be a far more likely cause of the anaemia. This leaves five in whom diet could be a factor; the importance of this is reduced if consideration is given to the group with a sliding hernia and short oesophagus, 80 of whom presented with dysphagia and were undoubtedly on very poor iron-containing diets, who did not suffer from a high incidence of iron-deficiency anaemia. These findings seem to exclude associated diseases or deficient diet as significant factors in the causation of anaemia.

Acceptance of the negative findings leads to the conclusion that bleeding is associated with the herniated stomach. A factor common to all cases is the to and fro riding movement during respiration of the stomach over the crura at the neck of the hernial sac. Large hernias, in which the force of this movement is thought likely to be greatest, have been found in 20 of the 59 patients in the series, and have been noted previously as being associated with a bleeding tendency by Sahler and Hampton (1943) and Flood (1960). Paraoesophageal hernias are probably more liable to this type of movement because the closed herniated stomach is subjected to a strong traction force on respiration (Fig. 1).

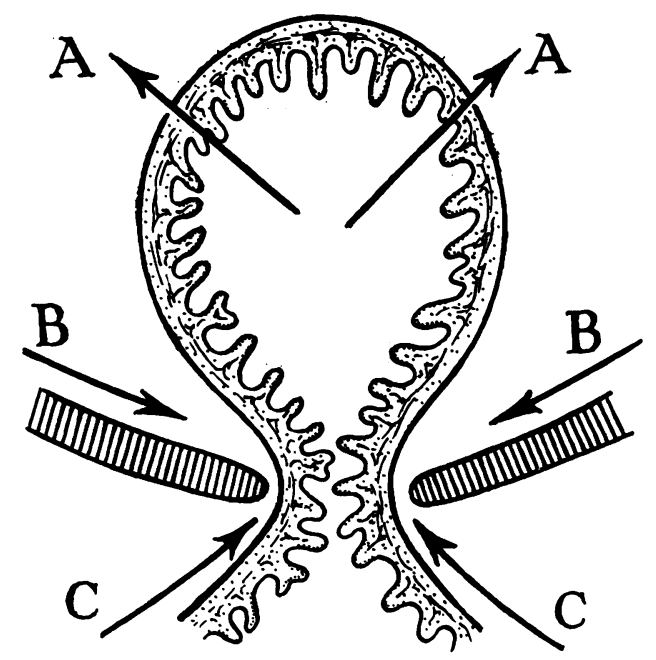

FIG. 1. Forces acting to damage the stomach mucosa at the neck of the sac during inspiration. A, negative intrathoracic pressure; $B$, crural muscle movement; $C$, sliding movement of the stomach.

Ulceration of the stomach at the point where it crosses the crus has been encountered in five patients in this series, and this gross change was 
associated with profound anaemia in three patients. Gastric ulceration, except in this area of the stomach, is an uncommon finding in association with hiatus hernia and would seem to be caused by some local factor such as the one already mentioned. The term 'riding ulcer' has been introduced to indicate the special nature of this type of gastric ulcer. Recently a careful examination of this area of the stomach has been made at operation and petechial subserosal haemorrhages have been demonstrated in five out of six cases (Fig. 2). It is thought that these changes represent the first stage of a series leading to frank ulceration of the mucosa at this site and that there is likely to be considerable trauma to the mucosa sufficient to result in haemorrhage before these late changes occur.

The dramatic effect of operation in the cure of anaemia and prevention of further haematemesis and melaena in all cases is a significant feature.
This further rules out associated disease as a contributory factor in the causation of anaemia since in no case was an additional procedure other than hiatus hernia repair (Collis, 1961) undertaken. Some of the patients who presented with weakness and anaemia had no other symptoms from the hiatus hernia; replacement of the stomach into the abdomen at operation was sufficient to reverse the iron-deficiency anaemia.

Two other possible causes of anaemia must be considered in this discussion, but it is not considered that they are very common contributory factors. Arterial and venous obstruction, mentioned by both Segal (1931) and Bock et al. (1933), leading to oedema and haemorrhage from the gastric mucosa may be encountered when the hernia is strangulated. In this series of 400 cases none of the anaemic group presented with symptoms of strangulation, neither were any of them found to have evidence of this at operation. This compli-
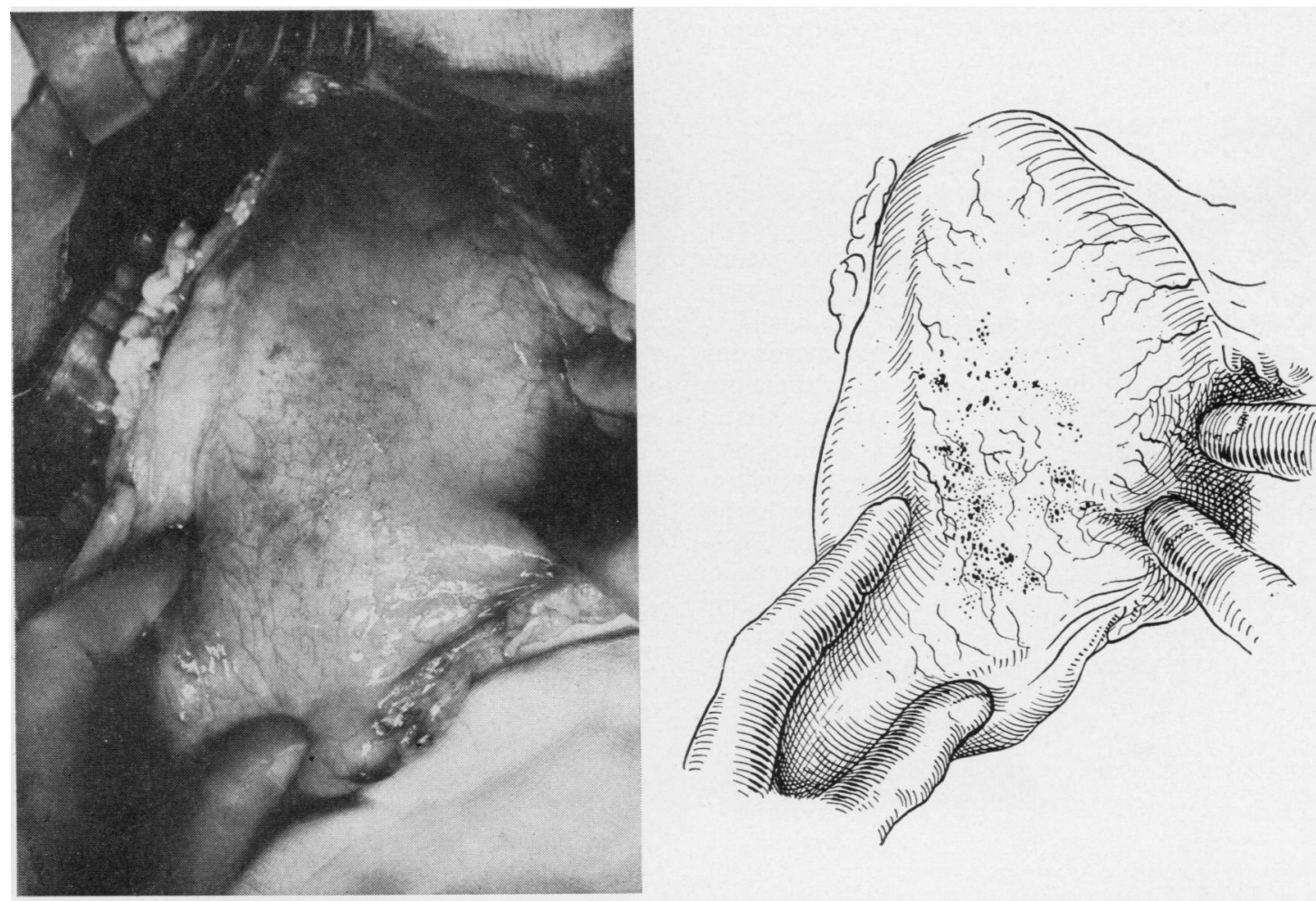

FIG. 2. Photograph taken during the operative repair of a paraoesophageal hiatus hernia. The stomach has been reduced from the sac. Gentle rubbing with gauze has produced petechiae in a band across the stomach in the area in which it has been in contact with the crura at the mouth of the sac. In this band there is also oedema of the stomach wall. These changes are in contrast to the state of the stomach in the sac above and the rest of the stomach in the abdomen below. 
cation was, however, noticed in several nonanaemic patients. The second possible factor is the effect of trapped gastric secretions in the stomach pouch on the mucosa of the herniated stomach. This has been referred to by Johns and Clements (1961) as a probable cause of mucosal damage ; however, it is thought that some gastric ulcers would have been found in the fundus of the stomach if this were so rather than at the neck of the hernia, as is described in this paper. A generalized gastritis could conceivably cause bleeding in some patients, but this probability needs further evaluation.

In conclusion, an attempt has been made to pinpoint the likely site of blood loss in patients with hiatus hernia. Mechanical trauma at the neck of the sac where the stomach rides to and fro over the crus during respiration is a factor common to all cases. Changes in this area varying from subserosal haemorrhages to frank gastric ulcer have been encountered in this series and have been associated with anaemia. It is considered likely that this is the commonest cause of anaemia in patients with hiatus hernia.

\section{SUMMARY}

Four hundred patients with hiatus hernia were studied and a $15 \%$ overall incidence of anaemia, melaena, or haematemesis was found. Anaemia was three times as common in the patients with paraoesophageal hernia as in those with a sliding hernia, $30 \%$ and $11 \%$ respectively. No correlation between this symptom and confirmed oesophagitis was found, neither was there any evidence that a deficient diet or associated disease played any part in the syndrome. Local trauma to the stomach at the site where it rides to and fro in the hiatus during respiration is thought to be the likely cause of the bleeding encountered, and arguments for this theory are put forward. The term 'riding ulcer' is used to describe the particular type of gastric ulcer found in some of these cases. A review of the literature on the association between $\overrightarrow{\vec{s}}$ hiatus hernia and anaemia is also presented.

Our thanks are due to Dr. W. Trevor Cooke and흠 his colleague Dr. Ann Benn for their advice and help in the preparation of this paper.

\section{REFERENCES}

Blades, B and Hall, E R (1956). The consequences of neglected hiatal hernias. Ann. Surg., 143, 822.

Bock, A. V., Dulin, J. W., and Brooke, P. A. (1933). Diaphragmatic-

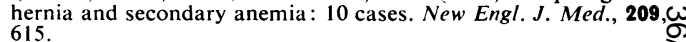
Bright, R. (1836); Account of a remarkable misplacement of the
stomach. Guy's Hosp. Rep., 1, 598.

British Medical Journal (1964). Anaemia and hiatus hernia. Brit. mediN $J ., 1,1061$.

Clerf, L. H., Shallow, T. A., Putney, F. J., and Fry, K. E. (1950)Esophageal hiatal hernia. J. Amer. med. Ass., 143, 169.

Collis. J. L. (1961). A review of surgical results in hiatus hernia. $\omega$ Thorax. 16, 114

Dagradi, A. E., Killeen, R. N., and Schindler, R. (1958). Esophageal hiatus sliding hernia: an endoscopic study. Gastroenterology, 35, 54.

De Vito, R. V., Listerud, M. B., Nyhus, L. M., Merendino, K. A., and Harkins, H. N. (1959). Hemorrhage as a complication of reflux esophagitis. Amer. J. Surg., 98, 657.

Flood, C. A. (1960). Clinical features of the management of esophageak hiatal hernia. J. Amer. med. Ass., 172, 314.

Forstner, G. G., and Bogoch, A. (1963). Gastritis of the herniated stomach in patients with esophageal hiatus hernia. Canad. med. Ass. J., 88, 16.

Grimes, O. F., and Stephens, H. B. (1957). The surgical treatment of esophageal hiatus hernia. Amer. J. Surg., 94, 194.

Harrington, S. W. (1940). Diagnosis and treatment of various types of diaphragmatic hernia. Ibid., 50, 377.

Hood, R. H., and McChesney, J. A. (1962). Hiatus hernia withô esophagitis and acute hemorrhage. J. Amer. med. Ass., 182, 243.을

Johns, T. N. P., and Clements, E. L. (1961). The relief of anemia by repair of hiatus hernia. J. thorac. cardiovasc. Surg., 41, 737.

Loeper, J., Rameix, P., and Moges, J. (1963). Contribution à l'étudeō de l'anémie des hernies diaphragmatiques. Presse méd., 71, 2775.3

Michaelides, G. J., and Philis, H. C. (1959). Pathogenesis and treat=ment of the anaemia associated with hiatus hernia. Lancet, 1, 552

Murphy, W. P., and Hay, W. E. (1943). Symptoms and incidence of anemia in hernia at the esophageal hiatus. Arch. intern. Med., 72, 58 .

Palmer, E. D. (1963). Hiatus hernia and hemorrhage. Amer. J. med. Sci., 246, 417.

Phear, D. (1957). Hiatus hernia. Lancet, 1, 708.

Roussak, N. J., and Eden, S. (1947). Severe anaemia due to diaphragmatic hernia. Brit. med. J., 2, 733 .

Sahler, O. D., and Hampton, A. O. (1943). Bleeding in hiatus hernia Amer. J. Roentgenol., 49, 433.

Schwartz, S. O., and Blumenthal, S. A. (1949). Diaphragmatic hiatus hernia with severe iron-deficient anemia. Amer. J. Med., 7, 501.

Segal, H. L. (1931). Secondary anemia associated with diaphragmatic음 hernia. N.Y. St.J. Med., 31, 692.

Truesdale, P. E. (1932). Gastric ulcer associated with diaphragmatio hernia. New Engl. J. Med., 207, 385.

Windsor, C. W. O. (1964). Gastro-oesophageal reflux after partia gastrectomy, Brit, med. J., 2, 1233 . 